\title{
Intervención arqueológica de apoyo a la restauración del torreón sureste de la Alcazaba de Guadix (Granada, 2005)
}

\author{
Bilal J. J. Sarr Marrocco * \\ Encarnación Reyes Martínez $*$ **
}

\begin{abstract}
RESUMEN
En este artículo se pretende resumir la intervención arqueológica de apoyo a la restauración del torreón sureste de la alcazaba accitana que se realizó en los aledaños e interior del mismo. El objetivo fue por un lado comprobar si tal torreón era a su vez un acceso a dicho complejo fortificado y por otro analizar el entorno de éste para alcanzar así una interpretación correcta de dicho sector
\end{abstract}

PALABRAS CLAVE: Arqueología Medieval. Guadix. Alcazaba. Torreón.

\section{INTRODUCCIÓN}

La ciudad de Guadix se ubica en la pendiente septentrional de Sierra Nevada, en el surco intrabético de la denominada Hoya homónima, a una altura de 900-1000 m. Es, sin duda, un lugar privilegiado y estratégico, de encrucijada de caminos relevantes desde antaño, debido al control del tránsito entre el levante y el valle del Guadalquivir y entre la costa almeriense y la meseta central.

Esta localización geográfica debe haber incidido en que Guadix sea uno de los núcleos habitados más antiguos de la Península Ibérica.

\begin{abstract}
In this article one tries to summarize the archaeological intervention of support to the restoration of the south-east tower of the Guadix fortress that was realized in the neighbouring places and interior of the same one. The objective was on the one hand to verify if such a tower was an access to the above mentioned fortified complex and, on the other to analyze the environment of this one to reach a correct interpretation of the above mentioned sector.
\end{abstract}

KEY WORDS: Medieval Archaeology. Guadix. Fortress. Tower.

Su nombre, Guadix, procede del vocablo árabe Wādī (río) y de la palabra Aš deformación de Acci, de origen ibero como otros topónimos Accinipo, Accitum, Tucci que contienen la misma sílaba -CCl (ASENJO SEDANO, 1983; p. 13). Posteriormente por procesos fonéticos como la imāla, de Wādī Aš se pasa a Wadiš más próximo al actual, como ya en el siglo XV se observa en el refranero de lbn 'Asīm. (IIMÉNEZ MATA, 1990; p. 276).

A pesar de la gran riqueza histórica no podremos dilatarnos en exceso en las etapas pre-musulmanas, aunque eso sí no debemos preterir ciertos datos básicos del acontecer de

\footnotetext{
* Becario de la Junta de Andalucía. Grupo de Investigación Toponimia, Historia y Arqueología del Reino de Granada. Universidad de Granada.

*** Arqueóloga.
} 
este territorio. Entre ellos la presencia de distintos restos arqueológicos prehistóricos en las terrazas fluviales del Fardes y sus afluentes.

Durante los siglos precedentes al Imperio Romano hallamos a Acci como un territorio sometido a los bastetanos, con centro en Basti como se observa en la Geografía de Ptolomeo $($ I883; II, 6,60). A estos pueblos se les atribuye la primitiva fundación de Acci. Tenemos información también de asentamientos fenicios y cartaginenses que se establecerían en estos territorios atraídos por su riqueza mineral (plomo, hierro y plata...).

Pero será en la época de dominio romano cuando la ciudad se reafirme verdaderamente como entidad urbana. Así con Julio César (4544 a.C.) se establece una colonia romana en la vega y sus colinas, que pasaría a denominarse Julia Gemella Acci. Ésta contará con el privilegio de acuñación de moneda que no perderá en la posterior época visigoda.

A través de los estudios epigráficos y numismáticos del profesor Mauricio Pastor Muñoz (en LAFUENTE, 1992; Est. preliminar) podríamos deducir que la ubicación de esta colonia estaría en la ciudad actual, aprovechando el antiguo poblado indígena. La abundancia de la cultura material lo pone de manifiesto.

En cuanto a la etapa de la Antigüedad tardía y altomedieval es escasa la información que disponemos de ésta. Aún no se ha resuelto la cuestión de su organización urbana, pese a que en los últimos años se ha contado con la aportación de la Arqueología, e incluso se ha elaborado un Proyecto de Arqueología Urbana.

Debió de darse la ruralización y degradación urbana propia de la crisis del Imperio romano y la llegada de los visigodos desde el 409, tampoco lograría restablecer el esplendor de tiempos antiguos. En este contexto se pro- duce la ocupación arabo-beréber. Ésta, aunque no tenemos mención concreta del hecho en Guadix, debió de ser en torno al 7/2. Lo que sí podemos señalar es que en el 713 `Abd al'Azīz b. Mūsà b. Nusayr debe reocuparla con motivo de una revuelta.

A partir de este momento Acci pasaría a denominarse por algún tiempo Madīna Banī Samī, ya que Sawwār b. Hamdūn concedería a los Banū Sam, árabes yemeníes, este territorio, que más tarde tomaría el nombre de Wādī Aš. (IBN Al-JAṬīB, Ihāța IV, p. 270.)

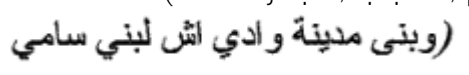

Hemos de reseñar también la expresión Arš al-Yaman o Arš al-Yamaniyyīn, con el que se cita la región en la que se incluiría Guadix, como nos aporta al-Himyarī, que lo toma de al- 'Uḍrī, o lbn al Jațîb.'

"El clima de Arš al Yamaniyyīn, con la ciudad de los Banū Sam b. Al-Muhalhil, es decir la ciudad de Guadix". (Al-Lamha 1980; p. 29) '

En los primeros siglos de dominación musulmana el actual Guadix tan sólo era un castillo situado en la actual alcazaba y de hábitat disperso (ASENJO SEDANO, 1983) pero adquiriría mayor importancia con el paso del tiempo. Así en el al-Muqtabis $\vee$ se cita, con relación a las expediciones militares de 'Abd al-Rahmān III en el $9 / 3$ contra los rebeldes partidarios de 'Umar b. Hafsūn ,a "los hūsūn o las fortalezas de Guadix":

"Luego se trasladó Al-Nāsir lidīn Allāh a los husūn de Guadix y sus caudillos huyeron por temor a él, y acampó en el hišn Fiñana el viernes 4 de Sawwāl" (Al-Muqtabis V; p. 66 árabe y 61 de la trad.).

Durante el periodo de mulük al-țawā if la ciudad pertenecería en un primer momento al Reino Zirí de Granada, pero en una de las incur-

\footnotetext{
I Tb. En SIMONET, I879; p. 127, pero se transcribe como "Orx". Pero como hemos indicado la forma correcta sería Arš .Ésta haría referencia a una tierra concedida como compensación o precio de sangre como señala Lévi-Provençal (1938; P.257).
} 
siones fronterizas sería anexionado por Ibn Sumādiḥ ${ }^{2}$ de Almería. Aunque posteriormente, Bādīs al-Muzzafar asedia Guadix y retoma esta ciudad para el reino zirí de Granada. Precisamente en esta etapa destaca el poeta lbn Haddād, que canta a al-Mu'țasim de Almería y alMuqtadir b. Hūd de Zaragoza después de huir del primero (RAMÓN GUERRERO, 1984; p. 31).

Poco sabemos de la Wādī Aš almorávide, sólo podemos citar el dato de la incursión de Alfonso I el Batallador en el II25.

Derrocados los almorávides, como sabemos se originan las segundas taifas, en las que destacará la sumisión de Guadix a Ibn Mardaniš ${ }^{3}$ desde el II50. En este siglo brillarían los poetas `Abd al- Mun 'in b. 'Umar, Ibn al-Barrāq, Abū-l- Hasan b. Nizāâr, ’Abd al-Barr b. Farsān y Hamda y Zaynab, hijas de Ziyād y sobre todo el excelso sabio Ibn Ṭufayl ( I | | 0 - | | 85) ${ }^{4}$.

En cuanto al califato almohade, la ciudad experimenta un importante crecimiento como todas las mudun de Al-Andalus. El radicalismo religioso de éstos hace que muchas iglesias se conviertan en mezquitas, como la de los Renegados en el arrabal mozárabe, y se margine a los ahl al-kitāb.

En torno a estos tiempos al-ldrīsī ( 1099 I 166) describe Guadix de la siguiente forma:

"Villa de mediana extensión, ceñida por murallas, en la cual se negocia mucho, está provista de agua en abundancia, y hay un arroyo que jamás se seca. [...] Guadix es el punto de reunión de muchos caminos" (Trad. SAAVEDRA, |881; p. 4I)

Esto reitera lo que veníamos señalando: Guadix va evolucionando desde un simple conjunto de fortalezas hasta una madīna considerable.
Pero es sin duda en época nazarí cuando la ciudad adquiere su máximo esplendor como integrante del Reino de Granada. De hecho el propio soberano Muhammad I se titularía alcalde de Guadix en 1232 como bien señala la profesora Jiménez Mata en su obra (1990; p. 277). En esta etapa se consolida la estructura urbana y sobre todo su alcazaba se convierte en una zona de difícil acceso como nos narra lbn al-Jațîb el Mi yār al-jitiyār.

"Goza de ventajosa situación, en lugar muy fuerte [...]. Su fortaleza pertenece a gente de la corona y es sede real" (Trad. CHABANA, 1977; pp. |30-|3|)

Sintomático de ello es el hecho de que a lo largo de este periodo muchos rebeldes y soberanos nazaríes depuestos se refugien en esta tierra. Probablemente también por ser un lugar estratégico desde donde se puede partir raudamente a la mar. El propio Muhammad $V$ destronado huye hacia Guadix como nos relata Ibn al-Jațîb:

"( Muhammad V) escapó del enorme peligro con corazón sereno y marchó bajo la negrura de la noche, con la sola compañía de unos jóvenes esclavos de su servicio y llegó a Guadix" (Trad. CASCIARO, 1998; p. 126)

En las postrimerías de Al-Andalus, durante las luchas intestinas entre musulmanes el Zagal ocupará Guadix pero no se demorará en exceso su resistencia a los cristianos, así tras la conquista de Baza, el 30 de diciembre de 1489 cae Guadix en manos de los trinitarios.

Por lo que como podemos comprobar la relevancia de tal madina y especialmente de su alcazaba no debe ser puesta en duda.

2 Memorias... p. 135 " porque Guadix con todos sus territorios anejos pasó a poder de Ibn Sumādị"”

3 miembro de una aristocrática familia de muladíes, como indica su nombre Mardanīš (Martínez, probablemente) nacido en Peñíscola en II 24 y muerto en Murcia en I 172, más conocido por el sobrenombre de "El Rey Lobo", llegó a convertirse en rey de toda la zona oriental de al-Andalus, Resistirá a los almohades hasta su muerte.

4 Sobre este autor es recomendable el artículo de Miguel Cruz Hernández, "Ibn Țufayl ", en Historia de la filosofía española. Filosofía hispano musulmana, Asociación Española para el Progreso de las Ciencias, Madrid 1957, tomo I, pp. 369-4I8. 
En cuanto a la configuración urbanística de Wādī Aš contamos con la aportación que realiza Asenjo Sedano sobre el siglo XV. Según éste la madína contaría con una extensión de $10 \mathrm{Ha}$., y los arrabales de otras $30 \mathrm{Ha}$. El recinto amurallado de la ciudad de Guadix se encuentra cerrando los barrios situados al norte de la alcazaba. El principal elemento conservado es el torreón del Ferro, situado en el ángulo noroeste del antiguo recinto amurallado, que conserva restos de los lienzos de las murallas $\mathrm{N}$ y O que partían de éste. Se trata de una torre de planta cuadrada de 7'5 m de lado, construida con muros de tapial de cal y canto sobre zarpa de mampostería que conserva una altura aproximada de 17 metros. En este aún se observan las huellas de los mechinales y restos de su enfoscado. La torre sería maciza a excepción del tercio superior. Éste estaría formado por una gran habitación, que en la actualidad ha perdido su cubierta, y que comunicaría los adarves de los lienzos de muralla situados en sus flancos $\mathrm{S}$ y $\mathrm{E}$. Aun se conservan los dos vanos, reforzados en ladrillo que darían acceso hacia el interior. En el vano $S$ se ven las vigas de madera del dintel.

La construcción se encuentra rematada por un almenado que se conserva de forma irregular en cada uno de sus lados. Así, en el frente $\mathrm{N}$ se observa la existencia de tres almenas; en su lado $\mathrm{E}$, el almenado ha desaparecido en su totalidad; en el $\mathrm{S}$ sólo se aprecia una almena, mientras que el $O$ posee una almena central y el resto de la coronación aparece en forma de peto. En este sector de la muralla se realizó una intervención arqueológica de apoyo a la restauración en los meses de julio y agosto del 2004. Como resultado, entre otras cuestiones, se puso al descubierto parte de una torre maciza de tapial de cal y canto que permanecía oculta bajo los escombros. Los materiales cerámicos estudiados en la intervención arqueológica dieron una cronología almohade a este sector del recinto amurallado. (MALPICA et alii, 2004).

La muralla oeste, paralela a la actual calle de San Miguel, llegaba desde el torreón del Ferro hasta el ángulo oeste del tercer recinto de la alcazaba. Parte de sus restos, los más próximos al torreón, se pusieron al descubierto al derribar unas casas que había adosadas a ella; es posible que todavía se encuentre oculto entre edificaciones posteriores y otros lienzos de muralla aparecen ininterrumpidamente a lo largo de la calle Almorejo, y le sirven a ésta como muros de contención, aparecen hasta ocho torres con lienzos de muralla intermedios, todo ello nos hace darnos una idea de la fortificación de la ciudad por esta zona. Están construidos con material de cal y canto, presentando bases del mismo material de mayor anchura que deja zarpas de metro y medio.

De la parte de la muralla orientada al norte quedan, además del lienzo que entesta en el torreón del Ferro, otro discontinuo que se extiende desde la fachada posterior del palacio de Villalegre hasta las cocheras del palacio episcopal, que se levanta sobre la muralla, y un tramo descubierto en la plaza de las Palomas. Las excavaciones arqueológicas realizadas recientemente tanto detrás del Palacio de Villalegre como en la plaza de las Palomas vienen a confirmar esta línea de muralla.

Son escasos los restos que quedan visibles del tramo SE de la muralla, aunque se conserva casi todo su trazado en la parte trasera de las casas de la actual calle Ancha. Seguramente toda la fachada sudeste del palacio de Peñaflor, situado anejo a la alcazaba, así como sus torreones, se han construido sobre la muralla de la se observan restos patentes.

La ciudad junto con sus arrabales quedaría protegida por una cerca exterior en la que diversas puertas darían salida a las ciudades cercanas. Tenemos noticias de estas puertas por la toponimia, por los restos que, aunque muy transformados, nos han llegado y por los trabajos arqueológicos realizados en la ciudad.

Por último, hemos de señalar la existencia de una mezquita aljama que se ubicaría bajo el solar que ocupa la actual catedral de Guadix, y de la que el viajero germano Jerónimo Münzer a su paso por la ciudad haría la siguiente descripción: 
"Es su mezquita bastante bella, y hexagonal. Tiene setenta columnas libres, y en el centro un jardín cubierto, en medio del cual hay una fuente viva para sus acostumbradas abluciones. Ahora está dedicada a la bienaventurada Virgen María." (MÜNZER 1494-95; p. 84)

\section{LA ALCAZABA DE GUADIX}

Las estructuras islámicas existentes en Guadix corresponden, por un lado, a las cercas de la madtna y, por otro, a la alcazaba. Esta última fue declarada BIC en 1931 y el casco histórico en 1976, en el que se incluye la fortificación. En noviembre del 2000 pasó a ser propiedad pública ya que con anterioridad a esta fecha era propiedad eclesiástica.

La alcazaba accitana está situada en el centro de la población y en su parte más elevada (952 metros aprox.), (foto I). Según la doctora Mazzoli Guintard se incluiría dentro de una tipología de fortificación muy particular comparable sólo con Baza y Loja. Ésta, nos señala la historiadora francesa, sería de hábitat permanente, próxima a la mezquita aljama, con encastillamiento y ausencia de albacar. (MAZZOLI, 2000; p. 172).

Tiene una planta ligeramente rectangular, redondeada en su ángulo sur. Las murallas del conjunto presentan como fábrica el tapial, estando levantadas sobre muros de nivelación de mampostería que disponen de zarpas. El conjunto ha sufrido diversas remodelaciones a través del tiempo por diferentes obras de restauración (Gómez Moreno), la última de las cuales, realizada alrededor de los años cincuenta, modificó considerablemente lo que sería su estructura originaria.

La fortificación se compone de tres recintos. El primer recinto, ubicado en el interior del conjunto, dispone de cuatro torres. La única que se asoma a la muralla exterior está situada en el lienzo SO, es maciza, construida en tapial y tiene un aljibe en su terraza que carece de bóveda. Al sur encontramos dos torres de planta rectangular, unidas entre sí por un paño de muralla con su adarve. Son macizas y están construidas igualmente en tapial, conservando grandes trozos de paramento enlucido con mortero de cal original. En este recinto y ocupando el centro de la alcazaba se alza una gran torre del homenaje, de planta cuadrada y construida en tapial, de la que aún se conservan importantes restos.

El segundo recinto rodearía al primero por los lados S y SE, disponiendo de un total de tres torres, dos pequeñas que salen de la parte redondeada que da al sur y otra, la de mayor tamaño de las torres exteriores construida en tapial de cal y canto, situada al SE y actualmente en proceso de restauración.

El tercer y último perímetro amurallado tenía su acceso desde la madtna por el lienzo noroeste a través de un portillo muy transformado. Este recinto con forma de $L$ abriga al primero y más elevado por los lazos NO y NE, carece actualmente de torres para la defensa siendo el sector en contacto con el interior de la madtna. Hacia el exterior en el ángulo $\bigcirc$ se levanta una gran torre. (MARTíN GARCÍA et alii, 1999; p. 216-219).

Uno de los problemas de la alcazaba es conocer la superficie que llegó a tener en época andalusí. Hoy día se conserva parte de ella pues tras la reconquista la familia nobiliaria de los Pérez-Barradas consiguió que medio recinto se seccionara del resto de la fortaleza aprovechándolo para edificar un palacio. En este sector se ubicaron igualmente los monjes agustinos. Por otra parte, como es común, las viviendas fueron enclavándose en el paño externo de la fortificación. En 1489, año de la conquista de la ciudad por los cristianos, ya se tienen noticias del mal estado en el que se encontraba la cerca defensiva especialmente en el sector de la medina. (ASENJO SEDANO, 1983; p.313).

\section{Antecedentes arqueológicos}

En 1986 se realizó una excavación de apoyo a la restauración en la zona más alta de la alcazaba. Dio como resultado la documentación de una serie de estructuras internas: aljibe, conducciones de agua, patio, muros, etc. Todo ello 
sobre el suelo virgen, constituido por arcillas verdosas muy compactas. Las estructuras documentadas fueron datadas a partir del s. X. Algunos fragmentos ibero-romanos que aparecieron mezclados con otros hispanomusulmanes estaban en una posición secundaria, provenían de otras excavaciones no arqueológicas cercanas o cabía la posibilidad de que viniesen de otra parte del cerro, muy remodelado y modificado por obras de aterrazamiento y nivelación. (RAYA DE CÁRDENAS, 1991).

\section{EL TORREON SE}

Es la torre de mayor tamaño de las torres exteriores situadas en el segundo recinto amurallado de la alcazaba. Tiene una planta rectangular de II'5 ×6 5 m y está realizada en tapial de cal y canto con reforzamiento de ladrillo en las esquinas. Se pueden observar dos plantas. La primera situada en la base se encontraba rellena de escombros y sellada con dos muros contemporáneos en el frente sur y en el frente norte, que fueron retirados para llevar a cabo los trabajos de consolidación y restauración. En la planta superior hay un receptáculo con muros de hormigón de cal que parece ser un aljibe. Esta planta tiene un vano de entrada de pequeñas dimensiones en la cara oeste. La torre está coronada por almenas.

La torre como el resto de la alcazaba ha sufrido abundantes restauraciones y reparaciones con hormigones modernos y materiales totalmente ajenos a la fábrica original.

Actualmente las mayores pérdidas de material se encuentran en la fachada sur del torreón, precisamente en este frente se iniciaron los trabajos de consolidación, (foto 2).

\section{LA INTERVENCIÓN ARQUEOLÓGICA}

Los trabajos arqueológicos se extendieron a lo largo de los meses de febrero y marzo del 2005, contando con el asesoramiento de D. Antonio Malpica Cuello, catedrático de Historia Medieval de la Universidad de Granada.

El planteamiento de la intervención se vio condicionado por ser una excavación de apoyo a los trabajos de consolidación del torreón SE, como parte del proyecto de parque arqueológico de la alcazaba de Guadix. Con tal objetivo se realizaron sondeos en el perímetro más inmediato al torreón. La excavación se divide en tres zonas:

- La zona I se ubica en el interior de la torre.

- La zona II queda en la cara norte.

- La zona III situada en la plataforma superior de la alcazaba a unos 10 metros de la cara E de la torre.

La superficie excavada suma un total de 90 $\mathrm{m}^{2}$ lo que supone un 0' $83 \%$ de la superficie total de la alcazaba accitana que cuenta en la actualidad con una extensión de $10.800 \mathrm{~m}^{2}$.

\section{ZONA I}

Se localiza dentro del torreón SE. Las dimensiones que presenta este sector, en el que se ha trazado un solo sondeo, son de 270 $\mathrm{m} \times$ 3'60 m. Antes de describir las diferentes unidades estratigráficas se ha de advertir que en esta zona se había actuado anteriormente con motivo de los trabajos de consolidación de esta torre-puerta (Diciembre-2004). Para dichos trabajos fue necesario retirar de forma manual la acumulación de escombros sitos en el interior del inmueble probablemente depositados para ser cegados los vanos de la cara sur y de la cara norte. Una vez que se llegó a una capa de relleno estable se paralizaron los trabajos de evacuación de escombros para utilizar dicha capa como suelo de apoyo de la estructura metálica que ha ayudado a afianzar el torreón SE, (foto 3).

A una distancia prudencial del andamiaje se procede a trabajar sobre el registro arqueológico, encontrándonos con un relleno contemporáneo de $79 \mathrm{~cm}$ de potencia, (UEN 00I). Se trata de una mezcla de tierra y material de construcción contemporáneo (teja, ladrillo), cerámica (contemporánea, moderna, medieval) y restos de fauna. Bajo ésta UEN se identifica la UEN 002 compuesta igualmente por un acopio de materiales más homogéneo de $24 \mathrm{~cm}$. de potencia. Tras ella documentamos 
un suelo de tierra y abundante cal grasa apisonadas junto con pequeños ripios y fragmentos de ladrillo. Se encuentra bastante deteriorado por procesos posteriores (las unidades estratigráficas anteriormente descritas).

Al mismo nivel que se identificó la UEN 00 I apareció junto a la entrada $\mathrm{N}$ del torreón SE un muro de ladrillos dispuestos de forma regular. Este muro presenta un grosor de 0'50 m y una longitud de 2'20 m a lo largo de la cara E del torreón. La altura máxima documentada es de 0'80 m y la mínima de 0'55 m localizada al inicio del muro junto a la entrada.

En la cara opuesta del torreón, es decir la cara $\mathrm{O}$, encontramos otro muro realizado en tapial de cal y canto, con igual orientación que el anterior. Conserva tres mechinales de $12 x$ $6 \mathrm{~cm}$. cada uno. Presenta unas dimensiones de de 2'20 m de longitud por 0'54 m de altura y 0'70 m de grosor, (foto 4).

Adosadas a ambos muros encontramos las jambas de una puerta. La jamba situada en la cara $\mathrm{E}$ del torreón presenta una altura máxima de 0'65 m y una mínima de 0'28 m y un grosor de 0'50 m, (foto 5). La longitud que se ha podido medir es de I'47 m aunque desconocemos la longitud real al no poder avanzar en esta zona del sondeo por motivos de seguridad. La jamba de la cara $\bigcirc$ conserva una altura máxima de 0'90 m y una mínima de 0'87m, un grosor máximo de 0'70 m y uno mínimo de 0'30 m, (foto 6). La longitud máxima que hemos podido medir es de l'40 m teniendo en cuenta lo que hemos apuntado para la otra jamba descrita. Ambas estructuras son de piedra arenisca con numerosos ladrillos adosados de forma irregular. Este hallazgo puede resolver una de las incógnitas fundamentales que nos planteamos antes de realizar esta excavación.

\section{ZONA II}

Se extiende inmediatamente junto a la cara norte del torreón, zona de entrada del recinto fortificado. En este amplio sector se realizaron cinco sondeos que acabaron uniéndose y conformando un cuadrángulo irregular de 67 $\mathrm{m}^{2}$. En general hallamos varias unidades estra- tigráficas que encontramos por todo el sector especialmente en la mitad norte donde se concentran las estructuras de época islámica descubiertas. Una vez retirada de forma mecánica la capa de hormigón que conformaba la antigua pista de fútbol documentamos tres unidades estratigráficas.

La primera de ellas y más reciente se compone de una acumulación de materiales de relleno depositados para nivelar el suelo y poder sobre éste construir la pista. Los restos encontrados lo ponen de manifiesto pues se han documentado abundantes fragmentos de cerámica especialmente contemporánea, fragmentos de ladrillos y tejas, cristales, goma, metal, cal y restos de fauna.

La segunda UEN, más antigua y ubicada bajo la anterior presenta una matriz compacta con presencia de cal. Es igualmente una capa de tierra mezclada con cerámica, fragmentos de ladrillo, rodillos de alfar y huesos. La cantidad de cerámica documentada es muy abundante y destaca principalmente la de época nazarí (dicho material cerámico está siendo objeto de estudio y será publicado).

Bajo la unidad anterior hallamos la última UEN compuesta por un fina capa de entre 8 y $15 \mathrm{~cm}$. de espesor, tratándose de una acumulación de restos de mortero mezclados con tierra situados sobre las estructuras de habitación documentadas. La matriz es muy compacta, de textura arenosa y de tonalidad grisácea clara a causa de la abundante presencia de cal. Mezclados con estos materiales hallamos cerámica nazarí, fragmentos pequeños de ladrillo y restos de carbón.

La zarpa de la torre aparece a una cota de -0'37 m de la superficie y está orientada SO$\mathrm{NE}$, (foto 7). Tiene unas dimensiones de 0'60 $\mathrm{m}$ de ancho por 5'60 m largo pues sólo se ha excavado bajo la zona de la fachada que queda al E de la puerta y bajo la misma. A poca distancia de la zarpa discurren dos atarjeas una de ellas identificada como moderna y que se encuentra a poca distancia de la superficie, y otra medieval, realizada con ladrillos y tejas, (fotos 8 y $8 b$ ). 
El sector NE es el que presenta mayor potencia arqueológica desde el punto de vista de las estructuras. El primer muro apareció junto al perfil $O$ del sondeo a una cota de 0'73 m de la superficie. Está orientado SE-NO. La longitud máxima que se conserva es de 2'74 m, un grosor máximo de 0'43 m y 0'36 m mínimo. La altura máxima es de 0'20 m. Fue realizado con ladrillo utilizando algunos mampuestos de tamaño mediano y varios fragmentos de teja, con una cimentación de mortero de tierra y cal grasa. Su estado de conservación es malo ya que se encuentra casi arrasado, (foto 9).

Junto al muro se desarrolla un suelo de ladrillos irregulares a una cota de -0'83 $\mathrm{m}$ del nivel superficial. Tiene 4'30 m de longitud máxima y un ancho máximo de I'30 m. Su orientación es SE-NO al igual que los muros. Se encuentra dividido por un desagüe o canalización (3 m × 0'l8 m) que carecía de cubierta, probablemente desaparecida con posterioridad, y su interior se encontraba colmatado por un relleno de una potencia media de 0'10 m, (foto I0). En la zona de salida de la vivienda el sumidero se halla cubierto por una laja de piedra y un suelo de ladrillos que encontramos a -0'67 m y que presenta una potencia de más de $0^{\prime} 10 \mathrm{~m}$, (foto II).

El muro que cierra la estancia por el E se adosa al suelo de ladrillos que queda al E del desagüe. Tiene una orientación SE-NO. Su extensión es de I'38 m, conserva un grosor máximo de 0'29 m, con una altura máxima de 0'20 m. Presenta una fábrica de ladrillos $(28 \times 14 \times 4 \mathrm{~cm}$.) dispuestos todos a tizón excepto cuatro en horizontal, (foto 12). El muro se asienta sobre un cimiento de mortero de tierra con ripios de 0' $15 \mathrm{~m}$ de potencia. Junto a este muro se encuentra una estructura relacionada con el uso del fuego realizada con fragmentos de teja y ladrillos con la superficie exterior quemada, (foto I3).

En el sector SE observamos, a una cota de -0'66 m de la superficie, la continuación del suelo documentado en el sector NE. Presenta una fábrica de ladrillos de tonalidad rojiza y anaranjada de tamaño irregular que parecen cons- tituir la entrada a la vivienda al encontrarse a una cota más elevada que en el sector NE y presentar unos ladrillos dispuestos de forma escalonada. Está orientado NE-SO.

Adosado a este suelo se levanta un muro perimetral realizado en tapial hormigonado con una orientación NE-SO. Se han podido tomar en parte sus dimensiones al situarse en una cota muy inferior a la que ha sido concluida la excavación. Observamos una longitud máxima de 2'60 m, un grosor máximo de 0'38 m y un mínimo de 0'24 m. El muro está arrasado apreciándose en superficie dos mechinales cuyas dimensiones son de 0'38 m de longitud por 0' 10 $m$ de ancho, (foto 14).

Sobre el muro se desarrolla un suelo de tierra y cal apisonada, muy rico en cal y con restos de ladrillos exfoliados, a una cota media de $-0,51 \mathrm{~m}$ de la superficie. Se conserva muy deteriorado por procesos postdeposicionales.

En el sector $N$ se localiza un suelo de ladrillos que forma parte del sector NE. Mide I'40 $\times 0$ 0'90 m. En el resto del sector se extiende un pavimento de cal y tierra apisonadas propio de un espacio de habitación o nivel de uso. El material cerámico permite encuadrar esta fase de ocupación en época almohade- nazarí.

En el sector $\mathrm{NO}$ encontramos parte de un suelo y un muro, ambos de ladrillo. El suelo está orientado NE-SO. Mide aproximadamente $2 \mathrm{~m}$ de longitud por 0' $80 \mathrm{~m}$ de ancho en la zona más amplia. Paralelo a este suelo discurre un muro localizado a una cota de -0'59 $\mathrm{m}$ de la superficie. Sus dimensiones son de l'65 m de largo por 0'30 m de ancho. Presenta como máximo tres tongadas de ladrillo a la cota anteriormente dada y una sola tongada a -0 '90 m. El muro se asienta sobre una cimentación de escasa potencia, de mortero de tierra con cal y pequeños ripios. Justo al $\mathrm{S}$ del muro se descubrió una fosa a una cota de -0'97. La fosa está orientada NO-SE y sus dimensiones son de $3 \mathrm{~m}$ de largo por I'30 m de ancho máximo y 0'70 m de profundidad. La fosa o balsa se hallaba colmatada por un relleno con abundante presencia de cerámica nazarí y moderna. 
En el ángulo NE de la fosa se descubrieron dos pilares de ladrillo que descansan sobre una cimentación de pequeño espesor de mortero de cal que se asienta sobre una capa de limos de tonalidad rojiza identificada como el estrato natural (-1 ' $62 \mathrm{~m}$ ). Ambos pilares los encontramos entre las cotas - I'20/-I'62 m. El pilar de la cara $\mathrm{E}$ conserva una altura máxima de 0'45 m, una mínima de 0'24 m y una anchura de 0'70 m. Muestra en su altura máxima 7 hiladas de ladrillos $(28 \times 12 \times 3 \mathrm{~cm}$.) de tonalidad rojiza. El pilar situado al norte y que se encuentra haciendo esquina junto al muro anteriormente descrito, tiene unas dimensiones de 0'60 m de altura máxima por 0'70 m de longitud máxima. Ambos pilares ofrecen sólo una cara quedando el resto soterrados.

\section{ZONA III}

Se traza en la plataforma superior de la alcazaba al $\bigcirc$ del torreón a una cota de 5'25 m respecto al sector II. En total se llevaron a cabo dos sondeos que suman una superficie excavada de $16^{\prime} 6 \mathrm{~m}^{3}$.

Se identifican dos unidades estratigráficas en este sector. La UEN 00 I localizada a nivel superficial está compuesta por un relleno de tierra de tonalidad parda clara y textura limo-arcillosa y suelta, mezclada con cerámica (contemporánea y medieval muy fragmentadas) y restos de material de construcción.

Bajo la UEN 00 I encontramos la UEN 002. Se trata igualmente de un relleno de materiales depositado con anterioridad a la unidad estratigráfica 001 . Se compone de una matriz más compacta de textura mixta (arenosa y limo - arcillosa), de tonalidad parda oscura. Hallamos entre las escasas inclusiones diversos fragmentos de cerámica algunos pertenecientes a un ataifor melado de época almohade, junto con distintos fragmentos de diversas épocas, material de construcción fragmentado y metal.

Justo en el perfil E del sondeo más cercano al torreón encontramos en superficie parte de un muro de tapial de cal y canto que conserva 70 centímetros de longitud, 70 centímetros de ancho y aproximadamente un metro de altura. Se observa que la fábrica original ha sufrido importantes alteraciones por restauraciones modernas.

Bajo el muro a 0'20 $m$ hacia el $E$ y a una cota de $3999 \mathrm{~m}$, encontramos un tramo de muralla de tapial con dirección SE-NO que ocupa la totalidad de la zona $\mathrm{E}$ del sondeo (2'50 m). Probablemente nos encontramos ante el tramo de muralla que se uniría con la torre del homenaje para cerrar así este sector de la alcazaba.

\section{UN PRIMER ANÁLISIS DE LOS MATERIALES CERÁMICOS}

La cerámica que hemos documentado en la alcazaba accitana es numerosa pero desgraciadamente se trata de piezas muy fragmentadas y en posición secundaria al formar parte de distintos tipos de rellenos. Por este motivo han aparecido restos cerámicos que abarcan una amplia cronología desde islámica a contemporánea.

En este avance del estudio de la cerámica de la alcazaba de Guadix, se han dibujado y descrito un conjunto de materiales islámicos.

La cerámica de cocina hallada corresponde a marmitas de cuello troncocónico y labio ligeramente engrosado al exterior. Las cazuelas presentan el borde en ala. Ambas piezas aparecen vidriadas al interior en tonalidades meladas.

Entre la cerámica de mesa los ataifores son las piezas más abundantes. Son ataifores vidriados en verde al interior $y$ al exterior pueden estar vidriados en melado o carecer de él. Presenta normalmente pie circular alto y mediano. El borde puede ser ligeramente engrosado al exterior o recto. Algunos ejemplares tienen perfil quebrado. Han aparecido fragmentos de jarritas pero son escasos. Son piezas de pastas claras amarillentas, algunas pintadas con trazos de manganeso y otras esgrafiadas sobre manganeso de las que se han encontrado paralelos en Baza (Granada). La serie redoma está representada por un ejemplar del que se conserva el cuello y el arranque del cuerpo y que 
recogemos dibujado. Está vidriado al exterior en verde oliva.

La vajilla de almacenamiento no es muy representativa al estar muy fragmentada, se conservan especialmente las bases. Hablamos de piezas de pastas rojizas y groseras.

Hemos documentado algunos candiles de pie alto vidriados en verde aunque ningún ejemplar completo, sólo aparecen los fustes y el arranque de la peana.

Las piezas destinadas a contener fuego, anafes, están compuestas por numerosos bordes que difieren en el tipo de grosor ya que son todos bordes triangulares engrosados al interior. Las pastas son rojizas y groseras.

Las piezas de uso múltiple se caracterizan a su vez por ser escasas. Documentamos alcadafes de bordes redondeados y engrosados al exterior que carecen de vidriado. Presentan pastas gruesas de tonalidad rojiza.

Finalmente, entre la vajilla de uso complementario tenemos tapaderas de dos tipos: tapaderas pequeñas de labio redondeado, borde en ala, cuerpo discoidal con asidero central y base plana; y tapaderas grandes planas con asidero central destinadas a cubrir grandes recipientes como tinajas. Los ejemplares pequeños tienen pastas de tonalidad rojiza y los grandes anaranjada.

\section{CONCLUSIONES}

Las estructuras descubiertas pertenecen a época islámica excepto una de las canalizaciones que parece ser más moderna y que está por excavar. Los niveles pertenecientes al ámbito de vivienda se han datado en época almohade-nazarí por el tipo de fábrica, por la cota a la que aparecen así como el material cerámico asociado al conjunto estructural. Las jam- bas de la puerta localizada en el interior del torreón SE (Zona I) creemos que pueden pertenecer al siglo $\mathrm{Xl}$, fecha en la que se erigiría posiblemente la fortificación.

Las estructuras localizadas en la zona III conforman un espacio de habitación. Desgraciadamente se encuentran en un estado precario de conservación.

Los materiales procedentes de la fábrica de estas estructuras (ladrillos), probablemente, fueron reaprovechados, de ahí que se conserven sólo las hiladas correspondientes al alzado de los muros. La conquista cristiana de la ciudad y la toma de la alcazaba a partir de I 489 daría lugar a la ocupación de las viviendas y demás recintos que la componen por los nuevos moradores. Esto explicaría que hayamos documentado material cerámico cristiano de primera época (s. XVI). En una primera etapa los cristianos darían el mismo uso a los edificios musulmanes posiblemente haciendo reformas en su estructura. $Y$ una segunda fase, la construcción de nuevos edificios provocaría el reaprovechamiento de materiales de los edificios antiguos.

No se ha documentado cerámica anterior a época islámica.

La lectura de los restos arqueológicos hallados resulta problemática dado el grado de destrucción y escasa ligazón entre las estructuras descubiertas. Esta situación es consecuencia de los numerosos trabajos de aterrazamiento y aprovechamiento de materiales a lo largo del tiempo.

La continuación de los trabajos arqueológicos en próximas campañas irá ofreciendo una visión más amplia y ayudará a comprender el sector excavado, pues hasta ahora tenemos sólo una visión sesgada de lo que fue parte de la ciudadela que integraba entre sus muros la alcazaba de Guadix. 


\section{FUENTES}

IBN HAYYĀN.- Al-Muqtabas V. Ed. CORRIENTES,F. Madrid, 1979. Y su traducción de VIGUERA, M.J. y CORRIENTE,F. Crónica del califa Abdarrahmán III an-Nasir entre los años 912 y 942 (al-Muqtabis V). Zaragoza, 198I, p. 61 .

IBN AL-JAṬT̄B: Al-Ihāța fĩ ajbār Garnāta. I-IV Ed. 'Inān. EI Cairo. 1973-77.

IBN AL-JATTīB: Al-Lamha al-badriyya fi ad-dawlah al-Nasriyyah .3 Ed. Beirut, 1980; p. 29, y en la versión traducida, Historia de los Reyes de la Alhambra: El resplandor de la luna llena (Al-Lamha al-badriyya); estudio preliminar por MOLINA LÓPEZ,E.; traducción e introducción de CASCIARO RAMÍREZ, José M. Granada, 1998; p.19.

IBN AL-JAṬ̄iB: Mìyār al-ljtiyār fĩ dikr al-Ma`hid wa-l-diyār. Rabat., 1977; pp.| 30-131 Texto árabe, traducción castellana y estudio por Chabana, M.K.

LÉVI -PROVENÇAL, E. Y GARCÍA GÓMEZ E.(Trad.): EI siglo XI en I a persona. Las Memorias de 'Abd Allāh, último rey zirí de Granada, destronado por los Almorávides ( 1090). Madrid, 1980.

MÜNZER, J.: Viajes por España y Portugal ( $1494-95)$, Nota introductoria de ALBA, Ramón. Madrid, |99|.

AL- 'UDRT̃: Tarsi al-Ajbar. "La cora de Ilbira (Granada y Almería) en los siglos $X$ y $X I$, según Al- 'Udrī (I0031085)". Trad. y notas por SÁNCHEZ MARTíNEZ, M. Cuadernos de Historia del Islam, 2, 1975-76.pp.5-80.

AL- 'UDRT̃: Fragmentos geográfico-históricos de al-Masālik ila gami al-mamālik. Ed. Crítica. 1965 AL-AHWĀNIT, `Abd Al-'Aziz. Madrid; p. 89.

PTOLOMEO: Geographie. Scriptorum Graecorum Biblioteca. París, | 883; ||, 6,60.

\section{BIBLIOGRAFÍA}

ASENJO SEDANO, Carlos (1983): Guadix, la ciudad musulmana en el siglo XV y su transformación en la ciudad cristiana del siglo XVI. Granada.

IIMÉNEZ MATA, M., C. (1990): La Granada Islámica. Contribución a su estudio geográfico-político-administrativo a través de la toponimia. Granada.

LAFUENTE ALCÁNTARA, M. (1992): Historia de Granada, I .Estudio preliminar por PASTOR MUÑOZ, M. Granada.

LÉVI-PROVENÇAL, E.( trad): La Péninsule ibérique au Moyen Âge d'après le kitāb al-Rawd al-Mi tār. Texte arabe des notices relatives à l'Espagne, au Portugal et au Sud-Ouest de la France. Leyde, 1938.

MALPICA CUELLO, A, ÁlVAREZ GARCÍA, J.J., CARVAJAL LÓPEZ, J.C., y REYES MARTÍNEZ, E. (en prensa): Informe de la Intervención arqueológica de apoyo a la restauración en el torreón del Ferro 2004. Guadix (Granada).

MARTIIN GARCÍA, M., BLEDA PORTERO, J., MARTÍN CIVANTOS, J. M. (1999): Inventario de arquitectura militar de la provincia de Granada (siglos VIII al XVIII). Granada.

MAZZOLI GUINTARD, C. (2000): Ciudades de Al-Andalus. España y Portugal en la época musulmana (siglos VIII$X V$ ). Granada.

RAMÓN GUERRERO, A (1984): Ibn Haddād (s. XI) y otros poetas de Guadix (s.XII). Granada.

RAYA PRAENA, I., BURGOS JUÁREZ, A., FERNÁNDEZARAGÓN SÁNCHEZ, I., LIZCANO PRESTEL, I., PÉREZ BAREAS, C. (2003): Carta Arqueológica de Guadix. Sevilla.

RAYA DE CÁRDENAS,I (199|): Excavaciones arqueológicas en la Alcazaba de Guadix (Granada) en A.A.A ; pp. I34-I38.

PÉREZ TORRES, C. (1989): Inventario de yacimientos arqueológicos de la provincia de Granada.

SAAVEDRA, E (| 88|): La geografía de España del Edrisí. Madrid; p.4I.

SIMONET, F.J. ( 1879): Descripción del Reino de Granada bajo los naseritas sacada de los autores árabes y seguido del texto inédito de Mohammed ibn Aljatib, Madrid. 

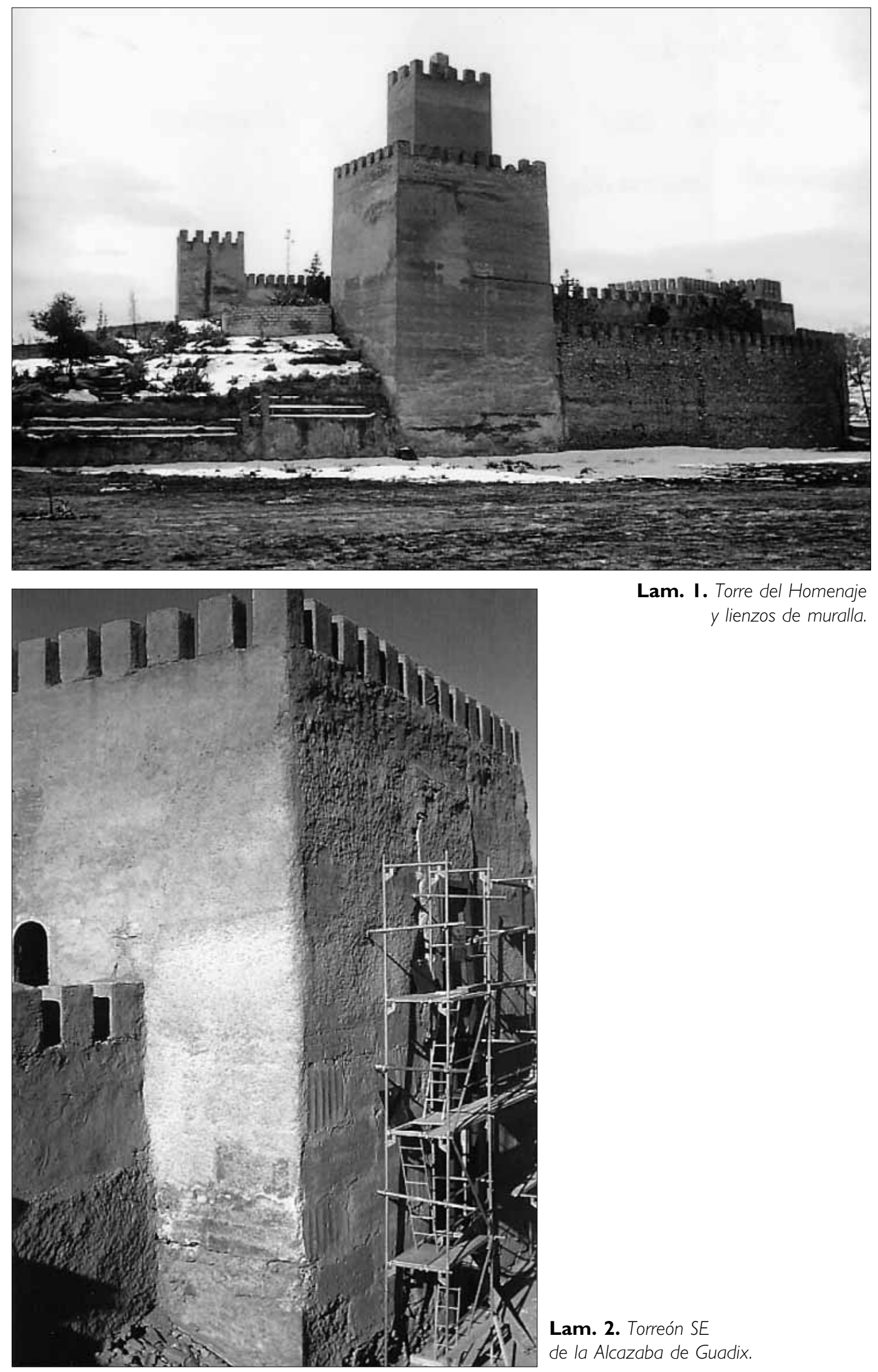

Lam. I. Torre del Homenaje y lienzos de muralla.

Lam. 2. Torreón SE

de la Alcazaba de Guadix. 


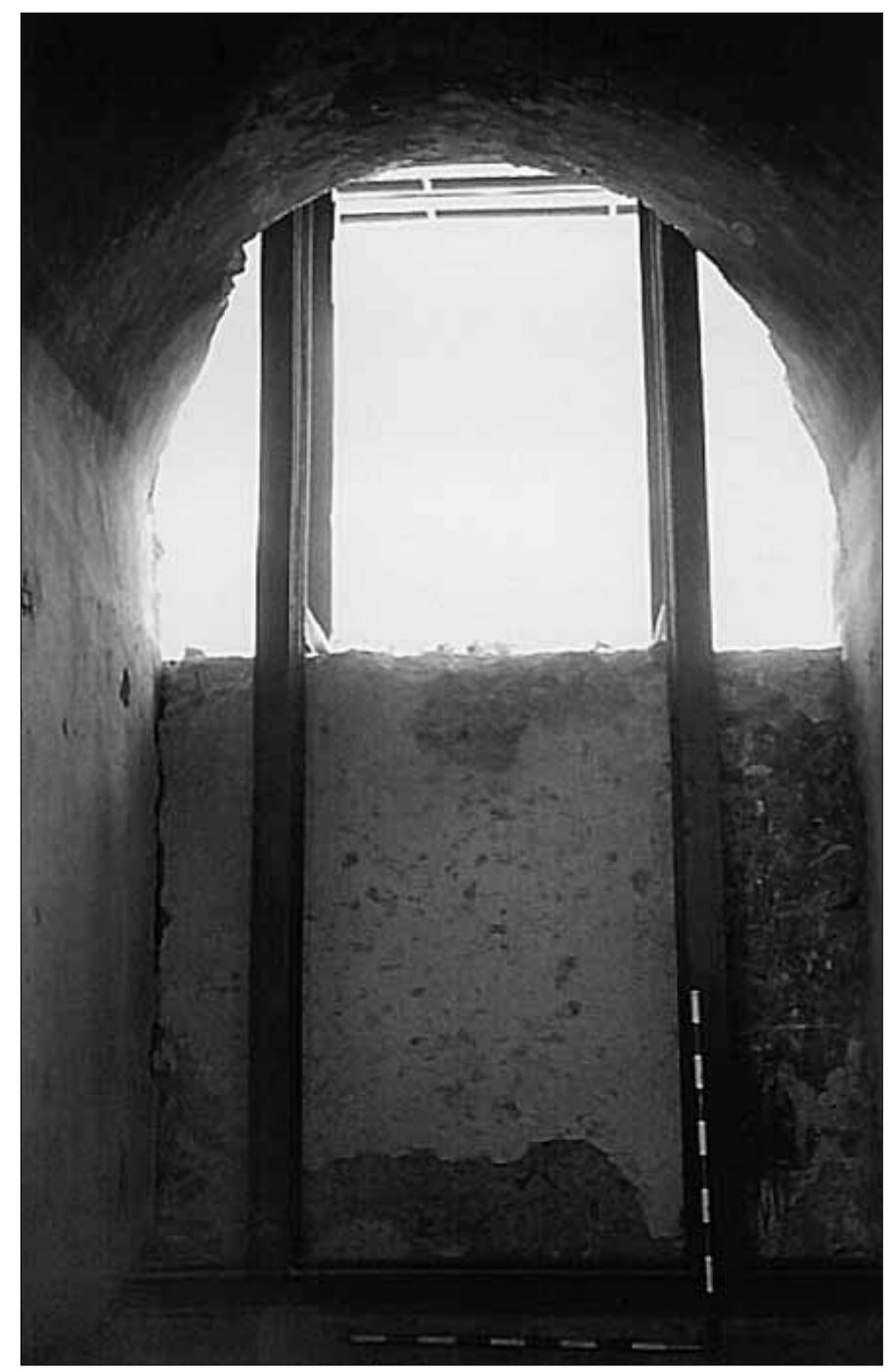

Lam. 3. Interior del Torreón SE.

Lam. 4. Muro de tapial (interior del Torreón SE).

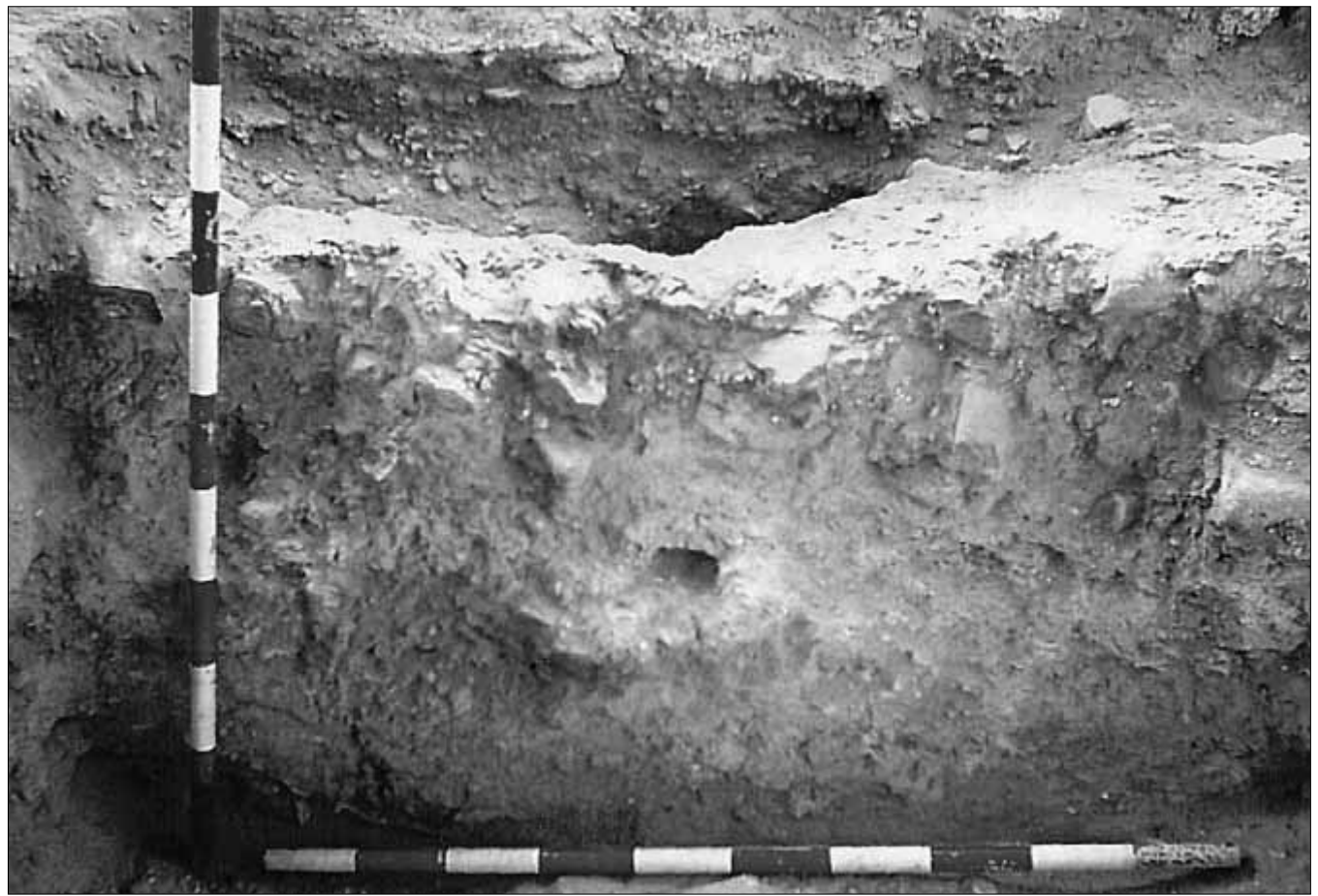




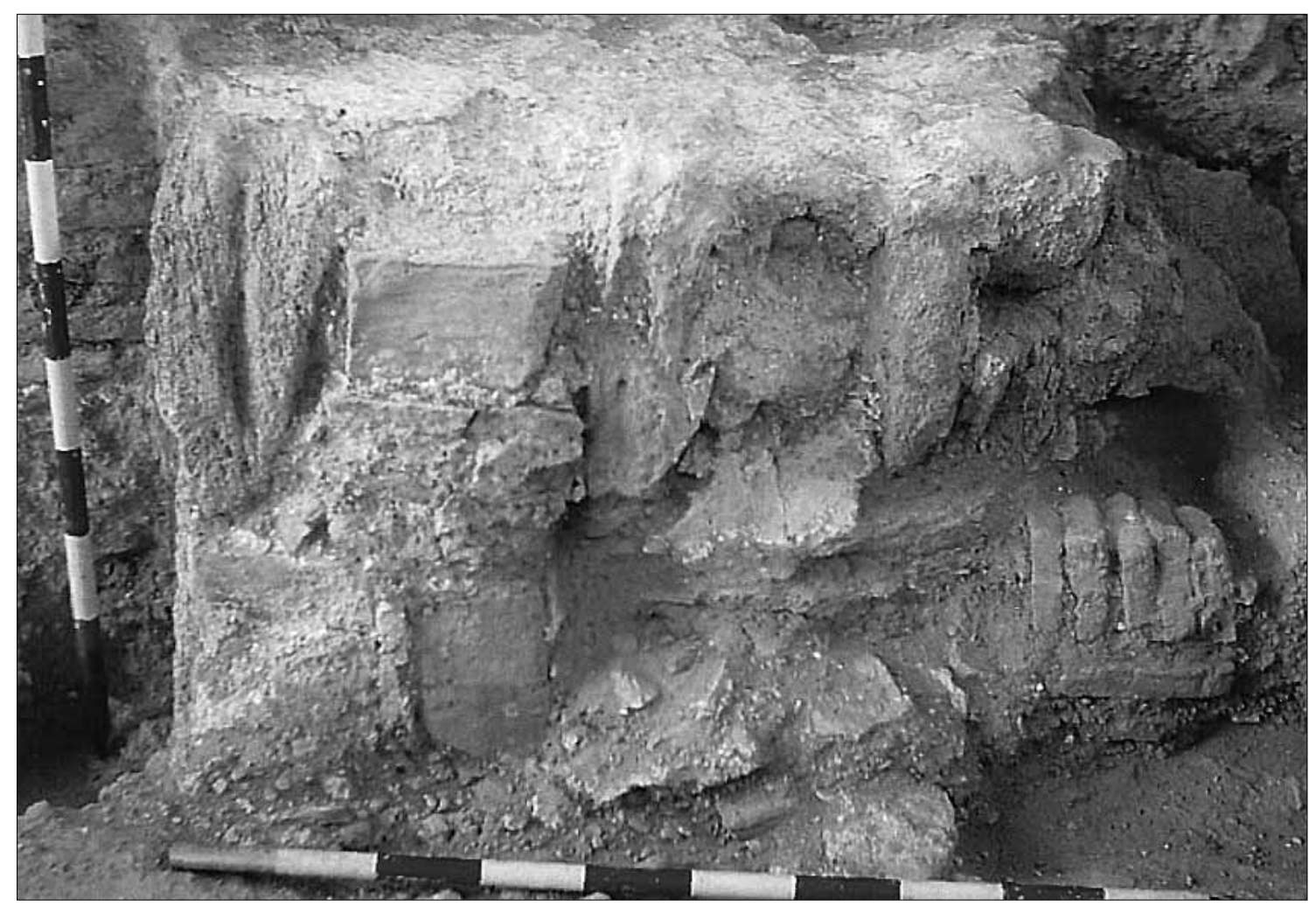

Lam. 5. Jamba E (interior del Torreón SE).

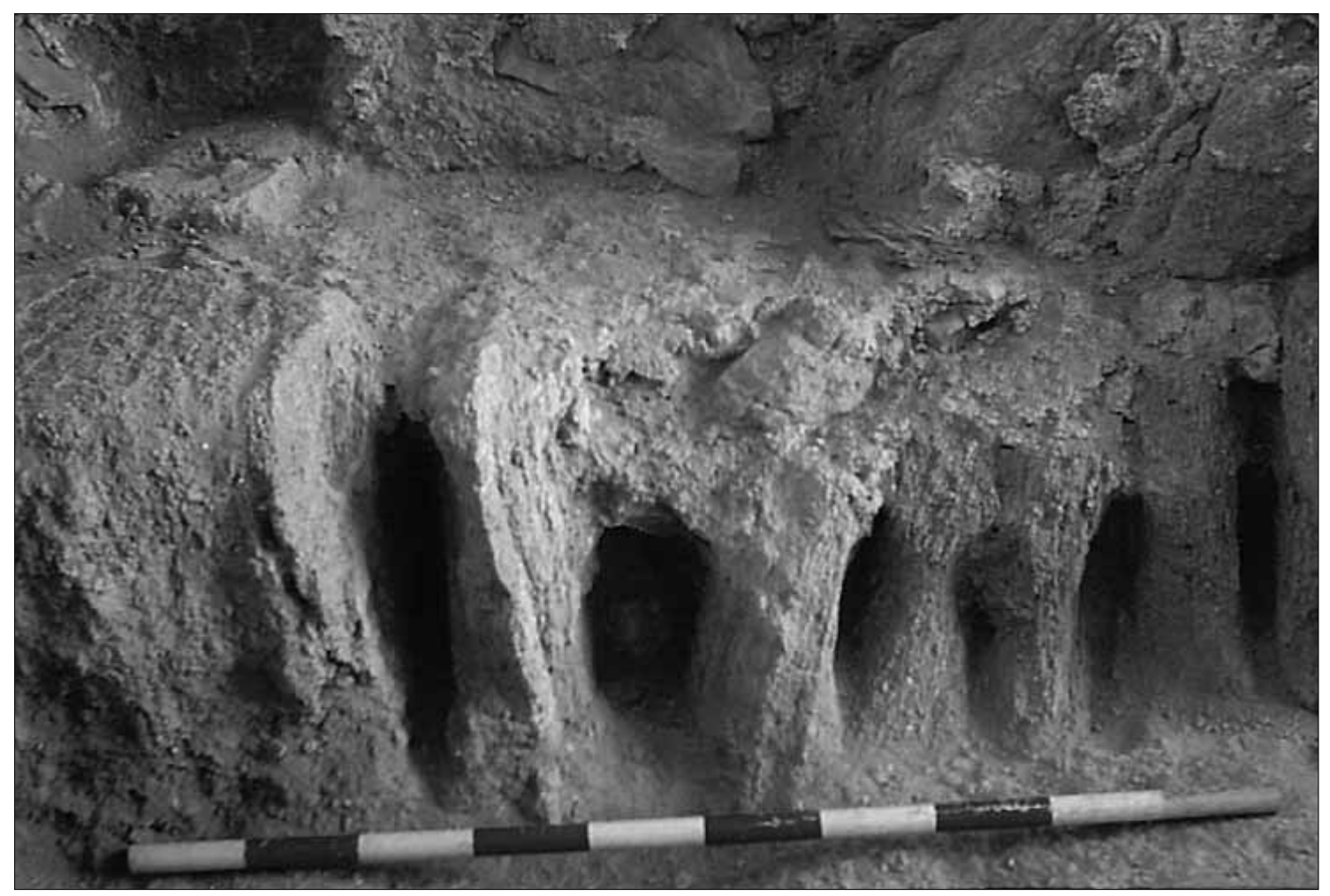

Lam. 6. Jamba O (interior del Torreón SE). 


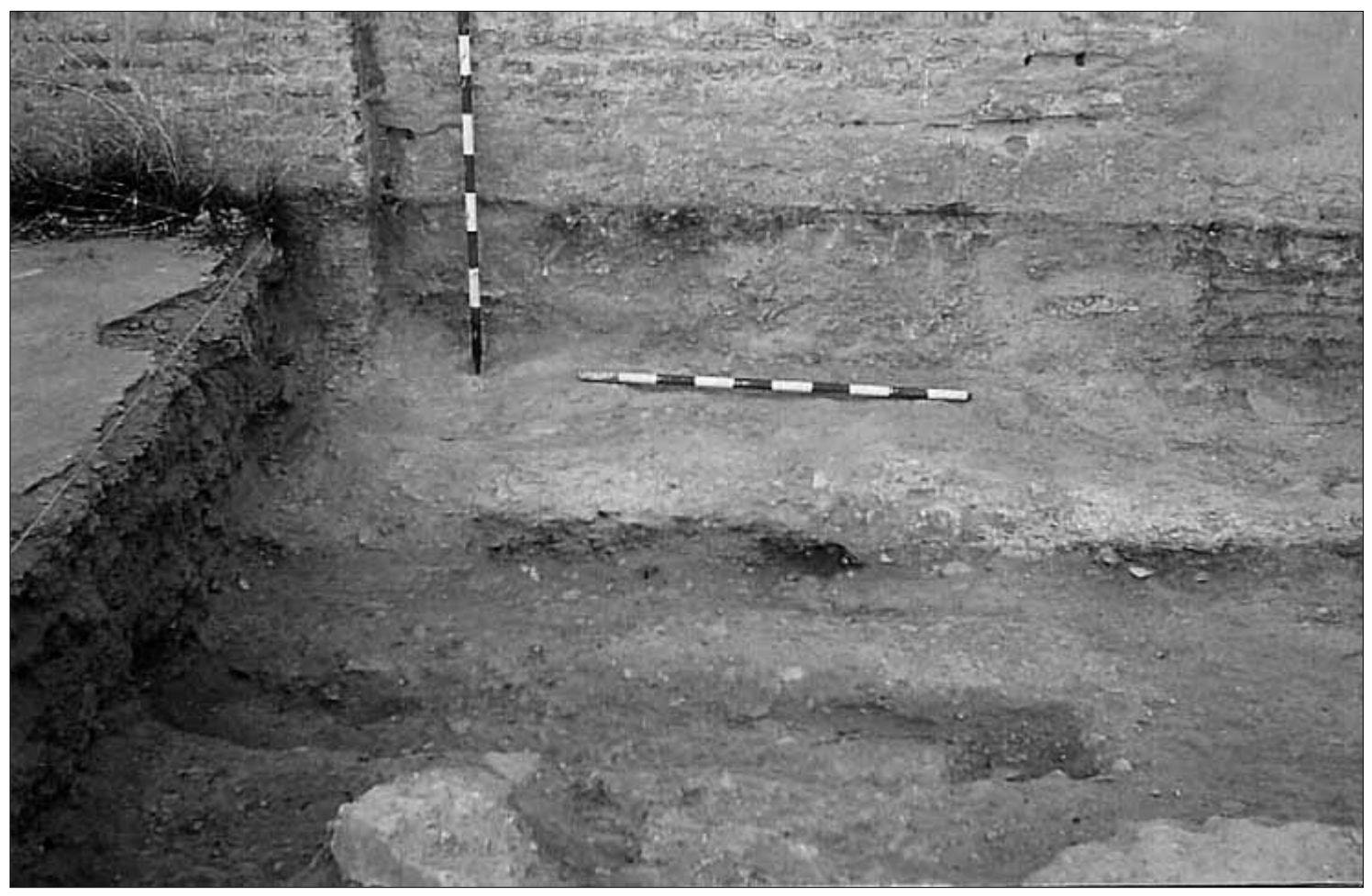

Lam. 7. Zarpa Torreón SE.

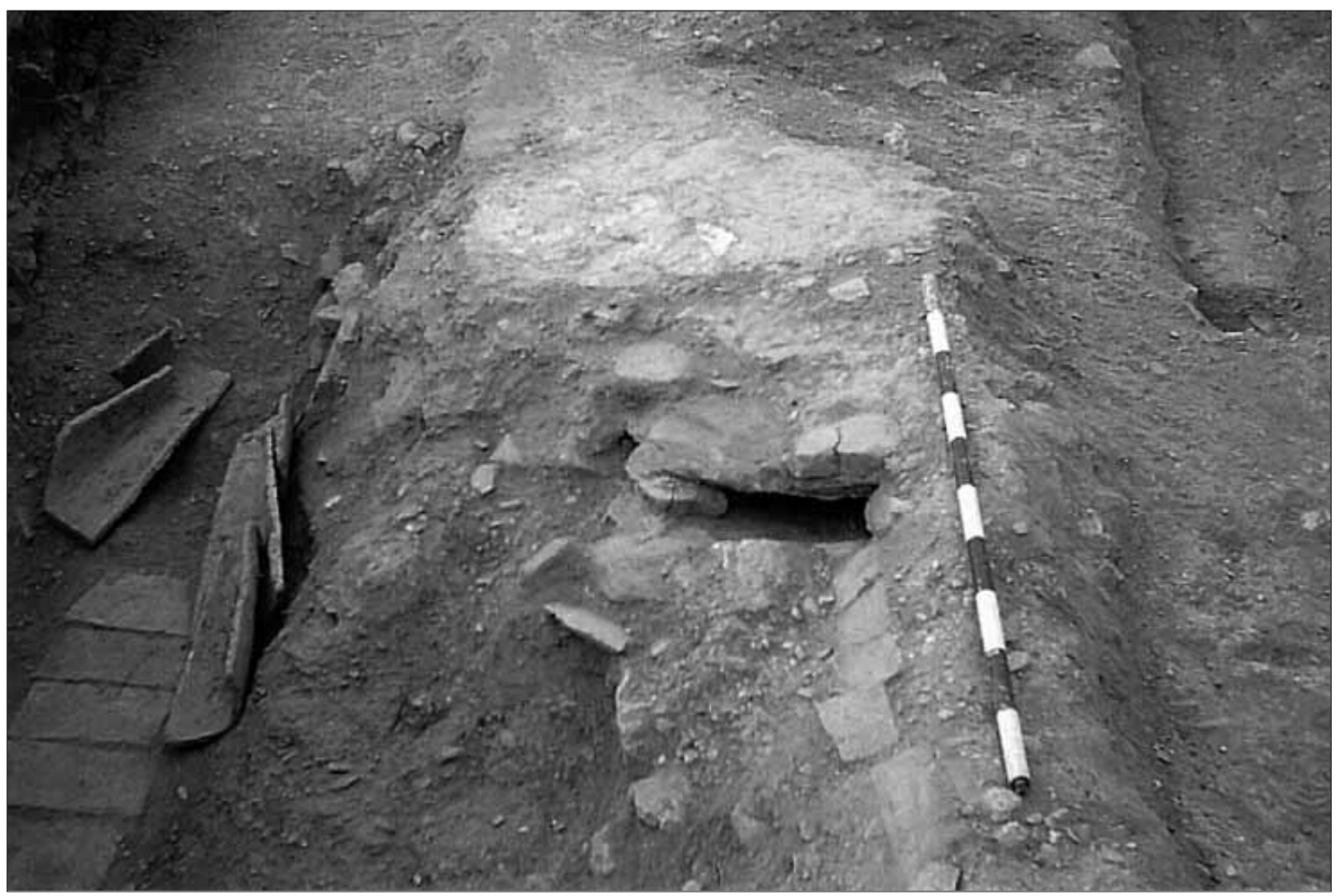

Lam. 8. Acequias localizadas en el sector inmediato a la puerta del Torreón SE. 


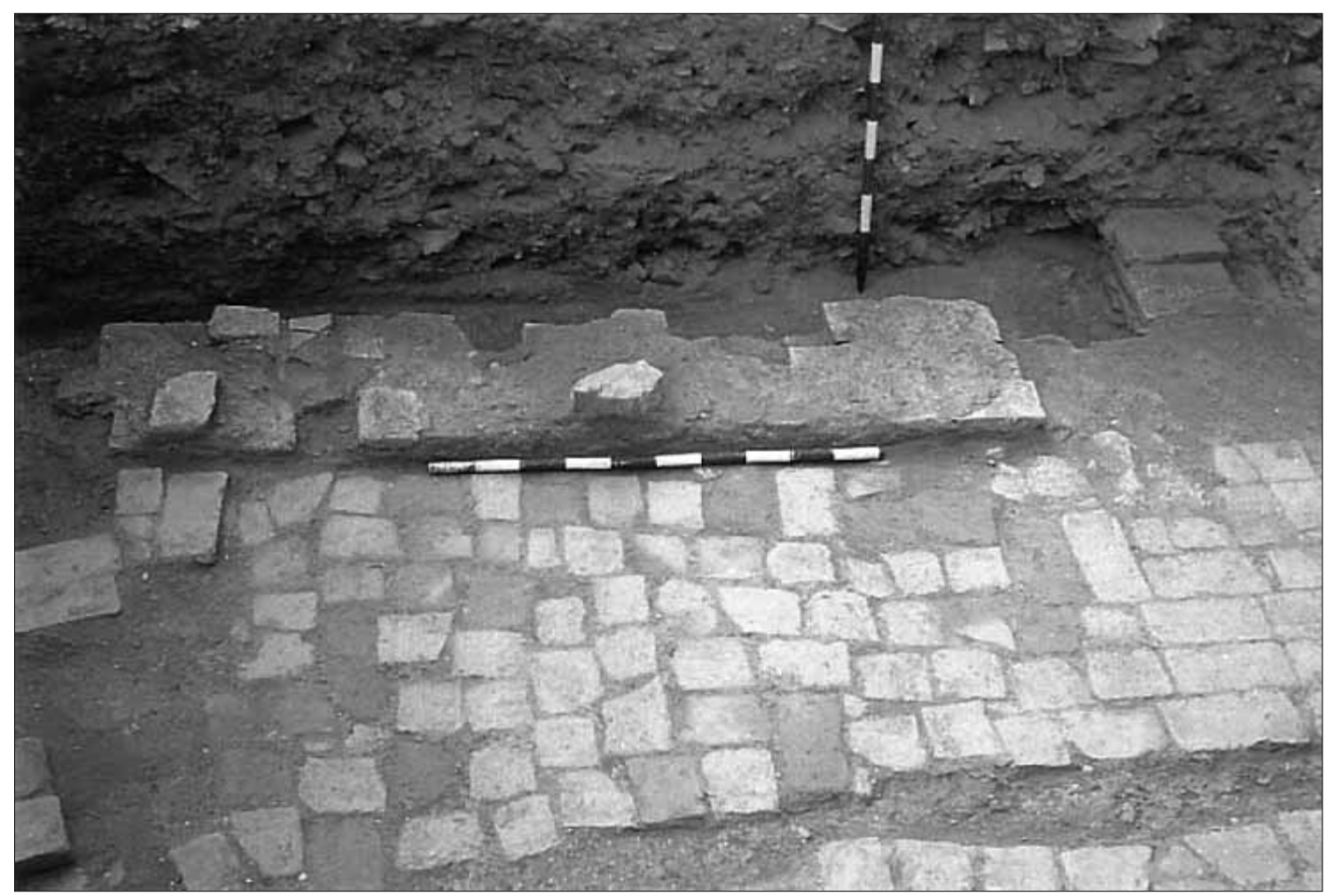

Lam. 9. Muro (Oeste) de la casa.

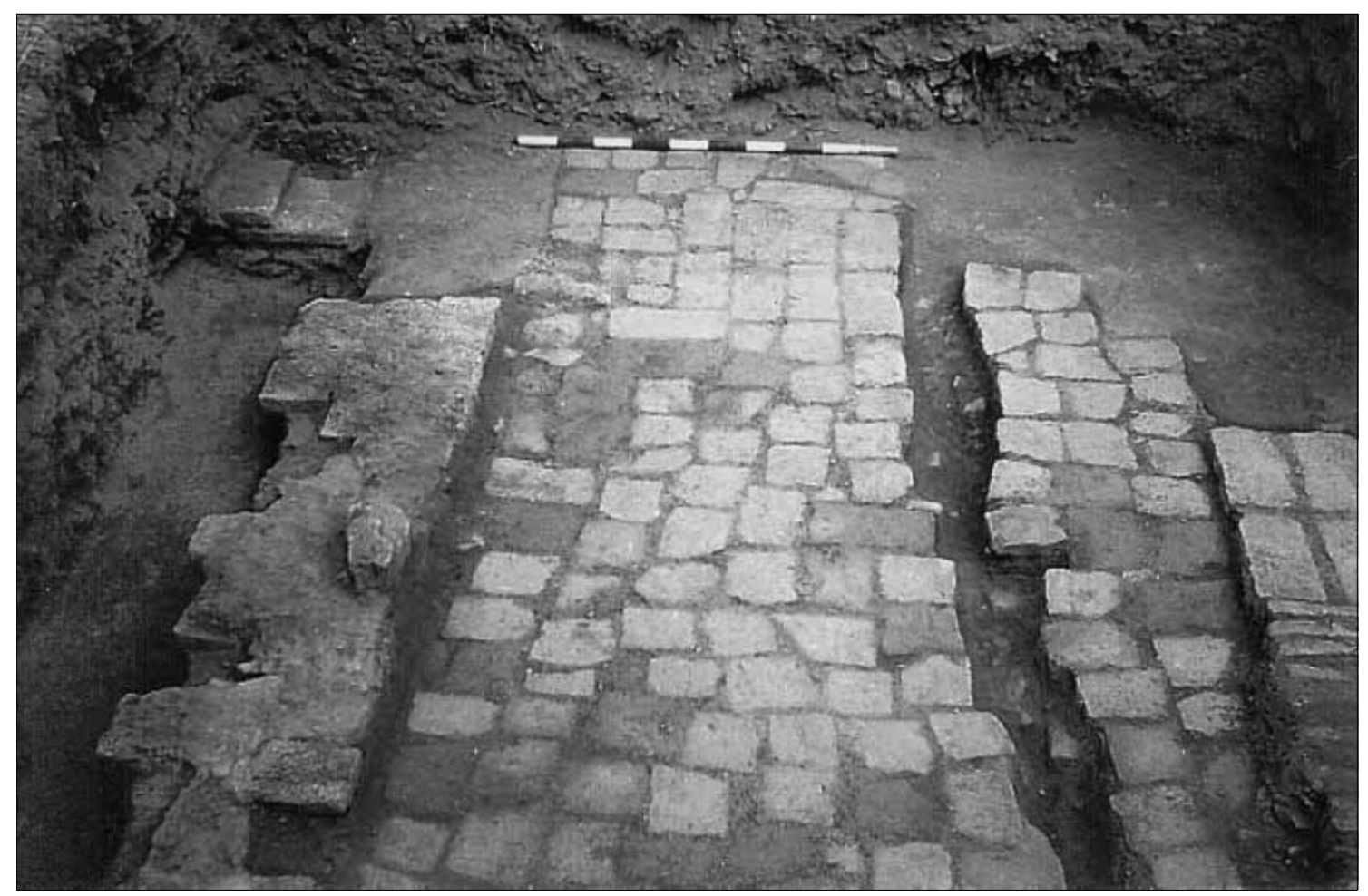

Lam. 10. Suelo de ladrillos y desagüe de la casa. 


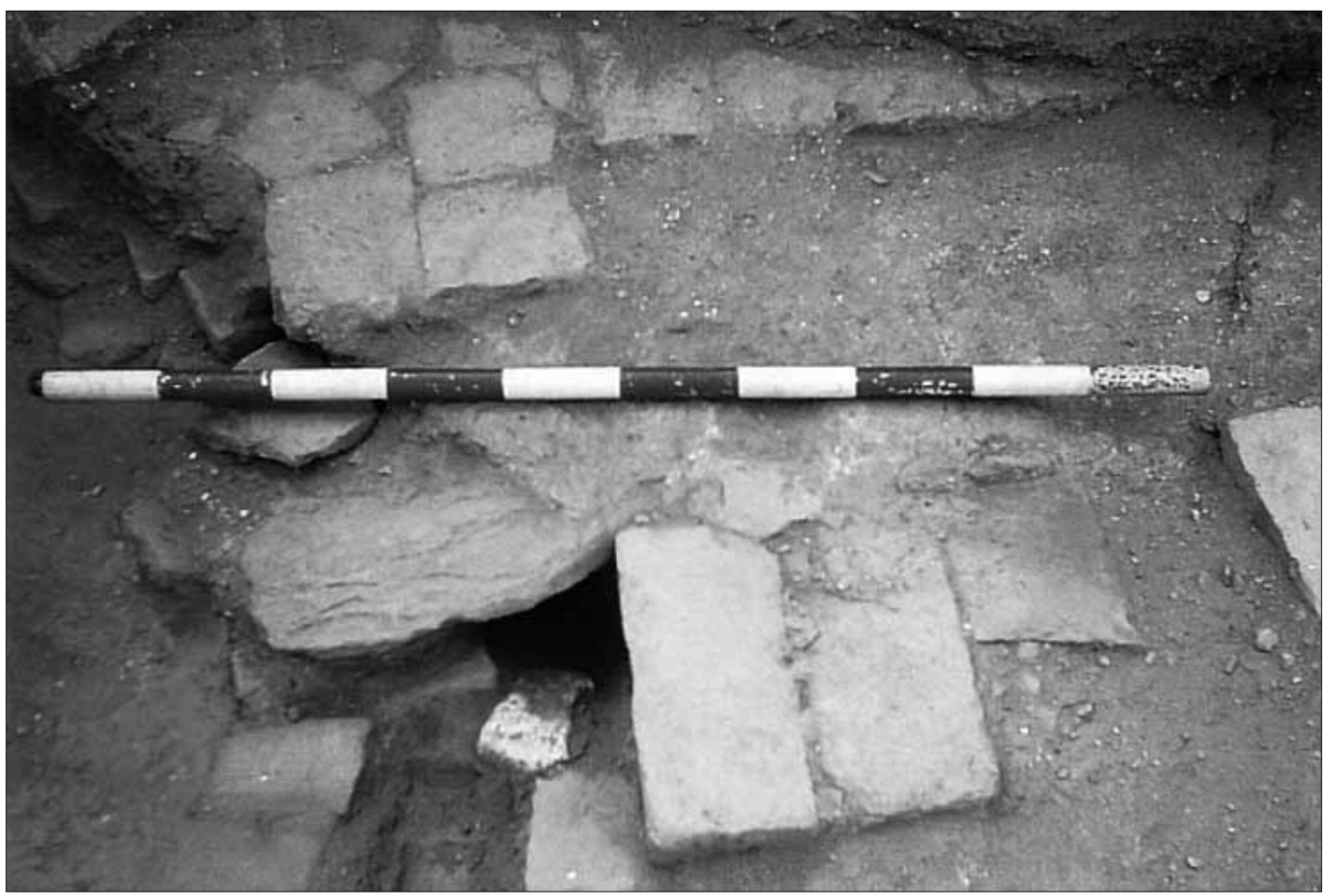

Lam. I I. Desagüe de la casa.

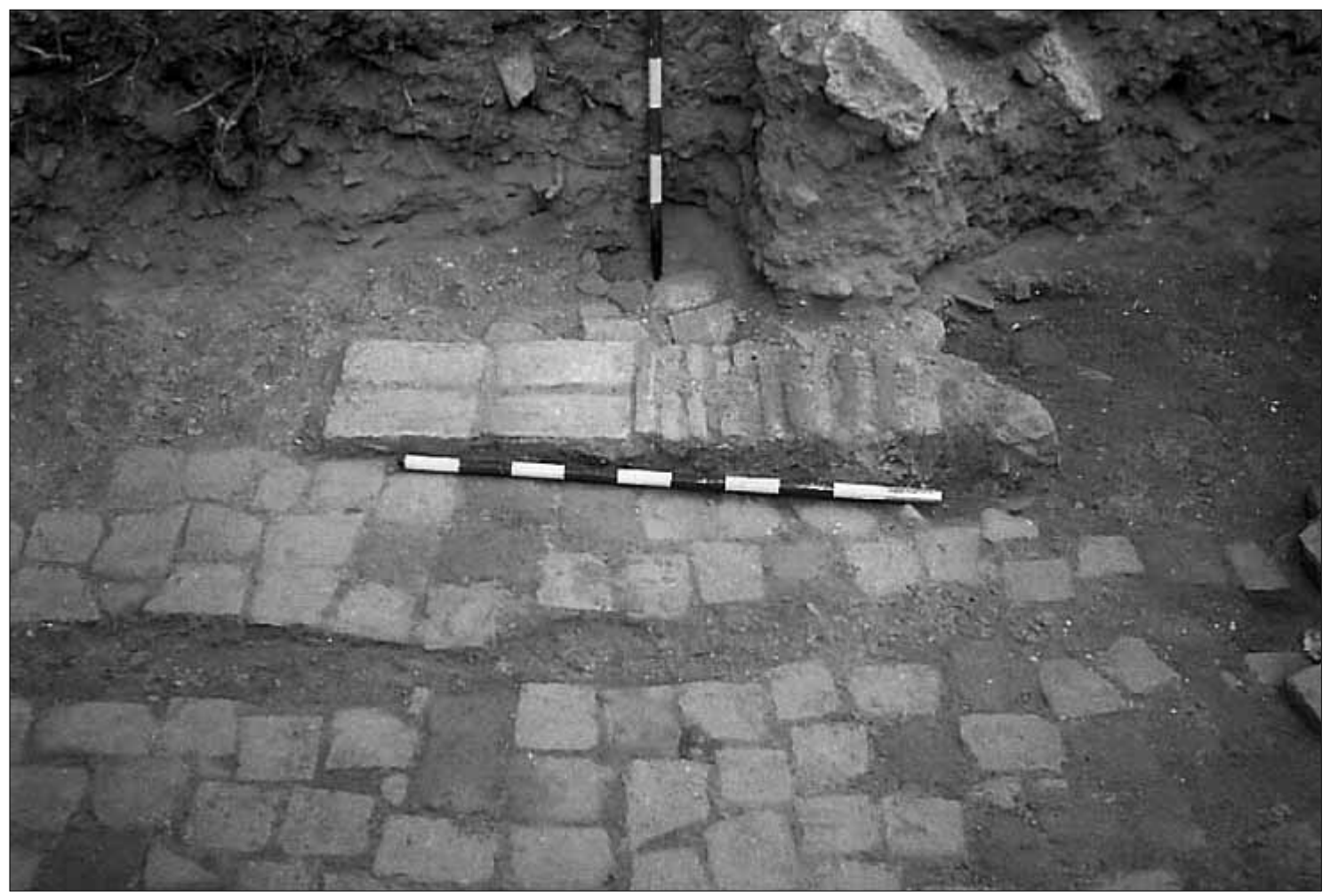

Lam. 12. Muro (Este) de la casa. 


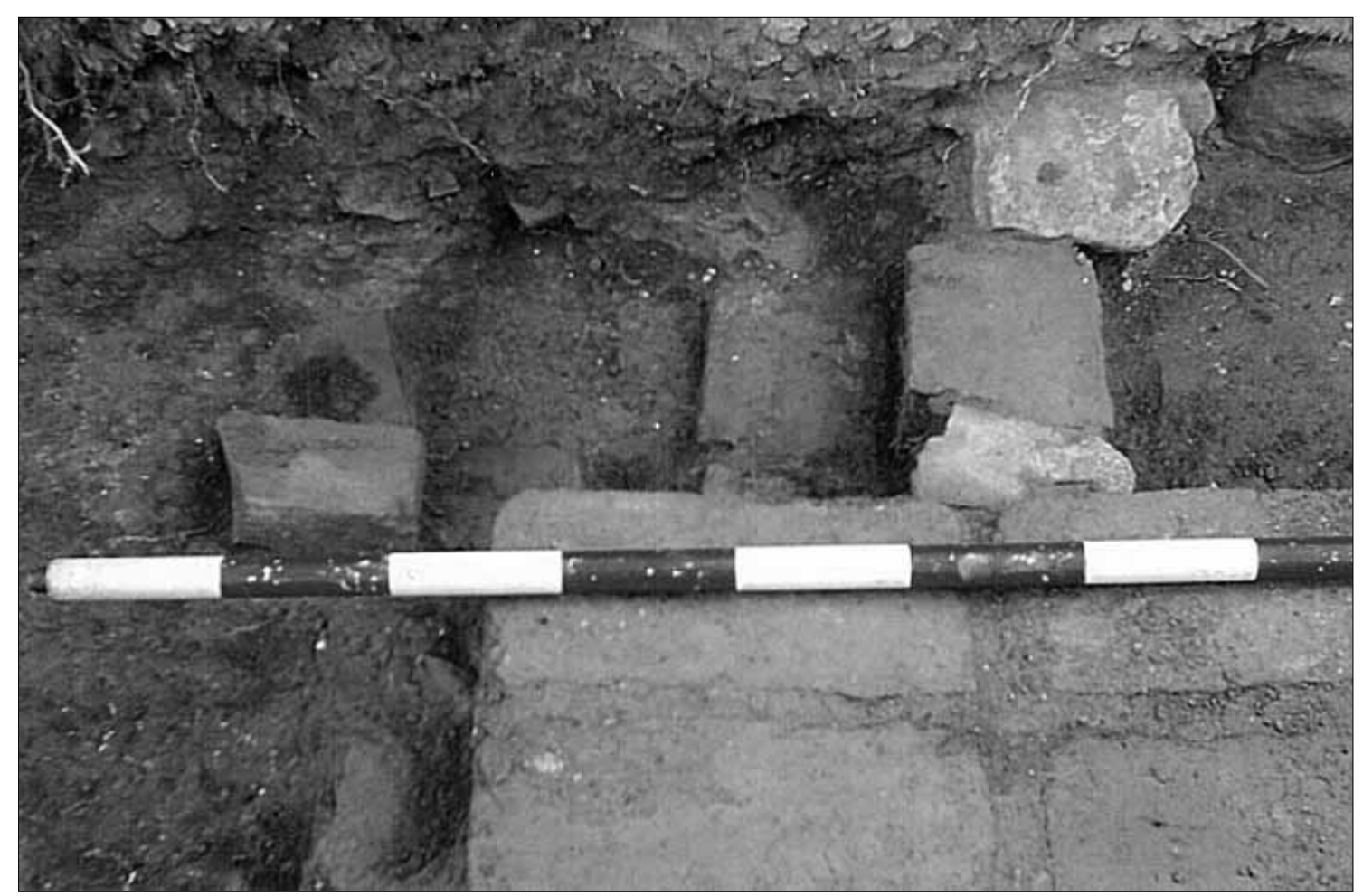

Lam. 13. Hogar o espacio de cocina.

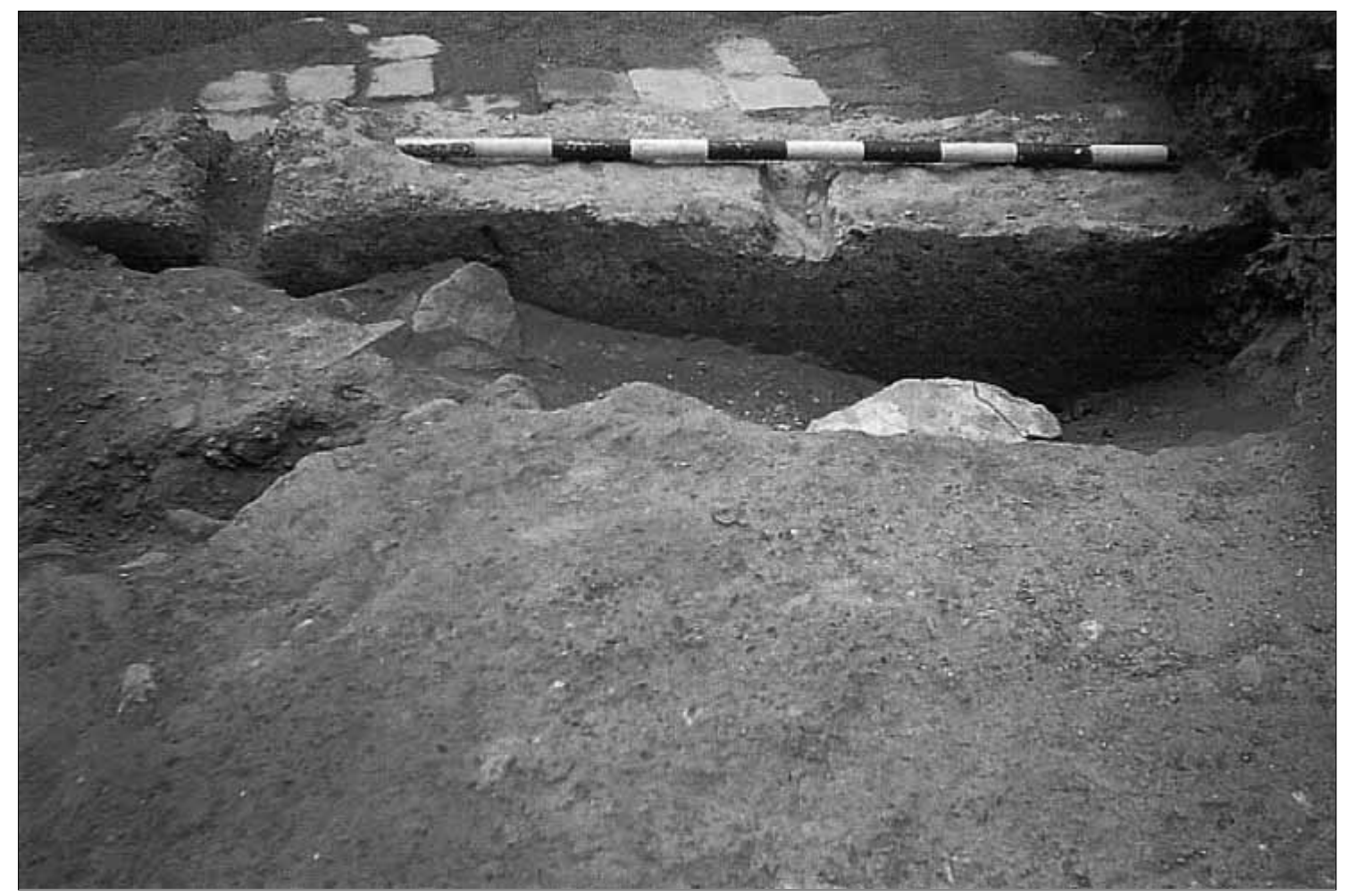

Lam. 14. Muro de tapial junto al desagüe de la casa. 